\title{
Abstracts of Papers \\ Twenty-ninth Annual Albert L. Tester Memorial Symposium, 11-12 March $2004^{1}$
}

The Albert L. Tester Memorial Symposium is held in honor of Professor Albert Tester, who, at the time of his death in 1974, was Senior Professor of Zoology at the University of Hawai'i at Mānoa. The faculty and students of the Department of Zoology proposed an annual symposium of student research papers as a means of honoring, in a continuing and active way, Dr. Tester's lively encouragement of student research in a broad range of fields within marine biology. Papers reporting original research on any aspect of science are solicited from students at the university and these papers are presented at the symposium, which takes place during the spring semester. Income from contributions to the Albert L. Tester Memorial Fund of the University of Hawai'i Foundation is used to provide prizes for the three best papers, judged on quality, originality, and importance of research reported, as well as the quality of the public presentation. Judges include Department of Zoology faculty members and the previous year's student award winners. In addition, a distinguished scholar from another university or research institution is invited to participate in the symposium as a judge and to present the major symposium address. In 2004 the distinguished visitor and judge was Dr. Philip J. Motta, professor of biology at the University of South Florida in Tampa, Florida.

\section{Distribution, Reproduction, and Movements of Parrotfish in the Azores ${ }^{2}$ Pedro Afonso-Santos ${ }^{3}$}

The parrotfish Sparisoma cretense sustains a growing gill-net fishery around the islands of the Azores, Northeast Atlantic. However, little is known about its life history and population dynamics. We conducted underwater visual census, biology, and acoustic telemetry studies to assess their distribution, reproduction, and space use. Parrotfish are abundant around the islands $\left(7 \pm 12\right.$ fish per $250-\mathrm{m}^{2}$ transect) and occur in a wide variety of hab-

\footnotetext{
${ }^{1}$ Manuscripts accepted 1 April 2004

${ }^{2}$ Coathors: Telmo Morato, Jorge Fontes, Kim Holland, and Ricardo Serrao-Santos.

${ }^{3}$ Department of Zoology, University of Hawaici at Mānoa, Honolulu, Hawai'i and Department of Oceanography and Fisheries, University of the Azores. Sponsor: Kim Holland.
}

Pacific Science (2005), vol. 59, no. 1:111-123

(C) 2005 by University of Hawai'i Press

All rights reserved itats, with a peak in abundance around 10 to $15 \mathrm{~m}$ depth. Size composition varied along the archipelago, with larger individuals being more abundant in those islands with less fishing pressure. Reproduction takes place from July to September. During that period, individuals either are territorial, with males forming harems in hydrodynamic coastlines, or they school and spend most of their time in sheltered bays, but both groups gather in the territorial areas during early morning when spawning takes place. Therefore, two different social and reproductive strategies seem to coexist in the population. Adult parrotfish display typically small home ranges, and information obtained so far indicates high site fidelity and reduced dispersion. Our results indicate that the netting fishery, which operates in sheltered coasts, might be impacting parrotfish populations considerably by selectively removing larger and schooling fishes. We argue that adequately enforced 
marine reserves of small to medium size might effectively protect core populations of this species within boundaries if they include connected habitats.

\section{A priori Optimization of Point-Intercept Sampling Christopher E. Bird ${ }^{4}$}

Point-intercept sampling is a popular and powerful tool for sampling the percentage cover of benthic species. Many researchers have empirically tested the accuracy and precision of point-intercept sampling against that of other sampling methods. Unfortunately, the results of these studies have been varied, with "system specific" conclusions, indicating that the accuracy of point-intercept cover estimates must be empirically determined separately for each system. Using a computer model to generate "quadrats" with various degrees of species richness, dispersion, and percentage cover and to analyze the quadrats with various numbers of randomly positioned point intercepts, we found random pointintercept cover estimates to be unbiased, precise, and predictable with the binomial equation for standard deviation. The absolute precision of a cover estimate is doubled by quadrupling the number of point intercepts, is the poorest at $50 \%$ cover, and increases as $0 \%$ and $100 \%$ are approached. When point intercepts are positioned in a stratifiedrandom fashion, the precision of cover estimates is, at least, equal to and often better than those obtained when point intercepts are positioned randomly. The magnitude of improvement in the precision is determined by the percentage of strata occupied, the size of a species patch relative to the size of a stratum, and the interaction of these factors. These results hold for photoquadrats from actual coral reefs and volcanic shorelines. As a result, one can quantitatively determine the number of points required to detect rare species or to detect a difference in percentage cover at a user-specified level of confidence with little or no exposure to the system to be sampled.

\section{Backward Blocking in Honeybees ${ }^{5}$ Rachel Blaser 6}

A systematic study of learning in honeybees has yielded results surprisingly similar to the results of studies of vertebrate learning. Given the differences in brain development and structure, these similarities suggest relatively simple mechanisms underlying learning. An important phenomenon in vertebrate learning, also found in honeybees, is blocking: rewarded experience with stimulus A $(+)$ followed by rewarded experience with a com-

\footnotetext{
${ }^{4}$ Department of Botany, University of Hawaici at Mānoa, Honolulu, Hawai'i. Sponsor: Celia M. Smith.

${ }^{5}$ Coauthors: P. A. Couvillon and M. E. Bitterman.

${ }^{6}$ Department of Psychology, and Pacific Biomedical Research Center, University of Hawai'i at Mānoa, Honolulu, Hawai'i. Sponsor: P. A. Couvillon.
}

pound of $\mathrm{A}$ and $\mathrm{B}(\mathrm{AB}+)$ appears to "block" learning about stimulus B. Recently, studies with humans have uncovered "backward blocking": experience with A+ after experience with $\mathrm{AB}+$ also appears to block learning about B. Our experiments were designed to investigate the possibility that backward blocking might be found in honeybees as well, suggesting a simple associative explanation of the effect. In two experiments, freeflying honeybees were trained to forage at a laboratory window for sucrose placed on targets labeled with odors. In the first experiment, responding to odor $\mathrm{B}$ after $\mathrm{AB}+$ training was less in the groups that were also given A+ training than in the control groups, whether A preceded, followed, or was con- 
current with the $\mathrm{AB}+$ training. In the second experiment, responding to $\mathrm{B}$ was less when the $\mathrm{AB}+$ training was followed by $\mathrm{A}+$ training than when it was followed by $\mathrm{A}-$ training. These results provide evidence not only of forward blocking but also of backward block- ing in honeybees, a phenomenon that contradicts the results of parallel experiments on within-compound association in honeybees. The same contradiction is to be found in the literature of vertebrate learning.

\section{Spawning Periodicity and Gametogenesis of the Fan Worm Sabellastarte spectabilis David R. Bybee ${ }^{7}$}

The sabellid polychaete Sabellastarte spectabilis occurs in calm, protected waters throughout Hawaici. There is very little published information on the biology of this fan worm, which is now in high demand for the marine ornamental trade. Understanding the reproductive biology of $S$. spectabilis will help to facilitate aquaculture of this polychaete. It will also benefit coral reef conservation by decreasing destructive collecting practices. Spawning periodicity and gametogenesis were investigated over a 1 -yr period. Twentyfive worms were collected from Kāne'ohe Bay each month. Sections $(7 \mathrm{~mm})$ of preserved worms were mounted on glass slides and stained using histological techniques. Gametes appear to be limited to abdominal seg- ments and absent in the thorax. Oogenesis is extraovarian. Primary oocytes are released into the coelom early in gametogenesis, where they will undergo vitellogenesis and a drastic increase in size before spawning occurs. Spermatogenesis also occurs in the coelom, where spermatocytes are released and undergo development, which involves a decrease in size. Oocytes were arranged into maturation stages (previtellogenic and postvitellogenic). Changes in the mean number of mature oocytes and presence or absence of sperm were compared with seasonal changes in water temperature and day length. Gamete development and observed spawning coincided broadly with changing water temperatures.

\section{Remote Tracking of the Manta Ray (Manta birostris) in Hawai'i Tim Clark $^{8}$}

The manta ray has come under increasing threat in the last $4 \mathrm{yr}$ due to a demand for dried manta ray gill filaments for a medicinal market in China. Given the long life, late maturity, and low fecundity of mantas, populations are highly susceptible to overfishing unless the population being fished is very large. Acoustic tags were placed on 28 mantas on the islands of Hawai' $i$ and Maui to investigate the home range of mantas in Hawaici.

\footnotetext{
${ }^{7}$ Department of Zoology, University of Hawai'i at Mānoa, Honolulu, Hawai'i. Sponsor: Julie Bailey-Brock.

${ }^{8}$ Department of Zoology, University of Hawai'i at Mānoa, Honolulu, Hawai'i. Sponsor: Kim Holland.
}

Tagged mantas were tracked remotely via an array of acoustic receivers along the Kona coast of the island of Hawai'i and on Maui. To date, no manta has been recorded migrating between the two islands. On Hawai $i$, tagged manta rays were detected along a $15-\mathrm{km}$ stretch of coastline in over $80 \%$ of detections, with only occasional detections outside this key area. Two locations where mantas showed exceptionally strong site fidelity are a known feeding area and a cleaning station. These data suggest that manta rays have a closed population in Hawaici, with little or no migration between neighboring islands. 


\section{Sea Urchin Diet and Its Possible Role in Defense Against Predation Tamar Saturen Cunha9}

After fish, sea urchins are the most visible herbivores on coral reefs. The collector urchin (Tripneustes gratilla) is a generalist, consuming an average of about $14 \mathrm{~g}$ of algae per day. In laboratory tests, $T$. gratilla showed little difference in consumption rates of several macroscopic algae (nonnative: Acanthophora spicifera, Gracilaria salicornia, Kappaphycus sp.; native: Dictyosphaeria cavernosa, Padina japonica), although it ate the smallest amount of Kappaphycus sp. (an average of $7.5 \mathrm{~g}$ versus $13-19 \mathrm{~g}$ of other species). When given two-option preference tests, subjects unexpectedly showed preferences for all choices over Dictyosphaeria cavernosa, including Kappapbycus sp. In a third test, urchins were found to prefer macroscopic algae over rocks with turf algae, although most of the differences were not significant. This is not surprising because $T$. gratilla is a browser and does not scrape the hard substrate to get to finer, filamentous algae as grazing urchins do. From the studies outlined here and other published data, we see that $T$. gratilla is a generalist herbivore. Many algae produce chemical defenses and those compounds vary between and within species. One important question is: how do the urchins biochemically handle this variance? Tripneustes gratilla is often found in the open on coral reefs and is active during the day, yet it seems to have few predators. I hypothesize that it avoids predation because it is unpalatable due to chemicals absorbed from the algae it has eaten. An analysis of various urchin tissues will show whether the urchins are able to sequester any of the algal compounds to make themselves less palatable food for potential predators.

\section{Population Biology of Scalloped Hammerhead Sharks (Sphyrna lewini) in Their Nursery Grounds \\ Kanesa Duncan ${ }^{10}$}

Nursery use is common in many species of sharks and represents a link between openocean and coastal energy systems. Like other large sharks, scalloped hammerheads (Spbyrna lewini) use nurseries throughout their range. The annual influx of newborn pups provides a large amount of biomass to the nursery, but pups also act as apex predators, seasonally dominating vertebrate biomass and consuming large quantities of food. Their role in the nursery's trophic ecology was quantified by combining estimates of population size, survivorship, residence time, and movement patterns with previously published energetic and food consumption data. Shark pups were

${ }^{9}$ Department of Zoology, and Hawai'i Institute of Marine Biology, University of Hawai'i at Mānoa, Honolulu, Hawai'i. Sponsor: John Stimson.

${ }^{10}$ Department of Zoology, and Hawaici Institute of Marine Biology, University of Hawai'i at Mānoa, Honolulu, Hawai'i. Sponsor: Kim Holland. found in Kāne'ohe Bay throughout the year, with highest catch rates in the deeper mudsilt habitat and highest population densities in midsummer. Although some sharks moved more than $5 \mathrm{~km}$ in a single day, most sharks were recaptured close to the initial point of release and within the expected activity range for this species, suggesting behavioral retention within the bay. Approximately 7,698 \pm 2,240 sharks are born into Kāne'ohe Bay each summer. Shark pups grow slowly in their first few months after birth and there is a significant trend toward lower fitness in late summer and fall, followed by increased growth rates during the winter. Mortality is as high as $90.6 \%$, but sharks that survive tend to remain within the nursery for at least a year. Even with this long residency time there is a positive influx of energy into the nursery. Thus, Kāne'ohe Bay may serve more as protection from predators than as a place of easy foraging. Whether this is a common nursery 
theme or an artifact can be determined by examining other nursery sites and testing hy- potheses of historic nursery use and related genetic lineages.

\section{Isolation, Characterization, and Expression of the Euprymna scolopes Apterous Gene Claudia Farfán ${ }^{11}$}

The gene apterous (ap) is best known for its fundamental role as dorsal selector gene required for wing patterning and wing growth in Drosophila melanogaster, but ap also has other important functions for neuronal pathfinding and fasciculation, fertility, and normal viability of the fruit fly. ap encodes a protein of the LIM-homoedomain subfamily. Many transcription factors of this class have been conserved during evolution; however in most cases it is not known whether structurally related genes play similar roles in different organisms. In this work I report the isolation, characterization, and expression of the Euprymna scolopes apterous homolog (Esc-ap). Isolation was carried out by RT-PCR and RACE techniques. Expression patterns were analyzed by whole-mount in situ hybridization. The Esc-ap is a composite full-length cDNA sequence 1,728 base pairs long with a predicted ORF encoding a predicted protein with 424 amino acid residues. This is the first time a full-length cDNA for the LIMbomeobox gene is described for a mollusk or any other lophotrochozoan. Esc-ap expression was detected in the earliest embryonic stage examined, stage 21 , and it was found in the eye placodes. By stage 23-25 high levels were found in the eye retina and all major ganglia of the central (CNS) and peripheral (PNS) nervous systems. In arms and tentacles expression was confined to the interbrachial nerves and base of the suckers. In older stages Esc-ap was downregulated or lost. These results suggest that Esc-ap is not involved in the patterning and/or growth of the brachial crown but has a major role in eye development and in both CNS and PNS development during the phase of most intensive ganglionic growth and axogenesis.

\section{Assessing Impact of Nontimber Forest Products Harvest on African Dry Zone Mahogany \\ Orou G. Gaoué12}

Despite the importance of nontimber forest products (NTFPs) for indigenous people as well as in international markets, the impact of their extraction has been overlooked by many scholars. Although NTFP extraction has been considered a priori sustainable, several lines of evidence suggest the contrary. The different uses of Khaya senegalensis (African dry zone mahogany) by indigenous people in Benin (West Africa) provide an interesting case study to investigate the ecological impacts of

${ }^{11}$ Department of Zoology, University of Hawaici at Mānoa, Honolulu, Hawai'i. Sponsor: H. G. de Couet.

${ }^{12}$ Department of Botany, University of Hawaici at Mānoa, Honolulu, Hawai'i. Sponsor: Tamara Ticktin.
NTFP harvest in tropical Africa using demographic as well as molecular genetic approaches. Khaya senegalensis is one of the rare fodder sources used by the Fulani tribe to feed their livestock during the dry season. Dry-season pruning pressure is so high that many trees fail to produce flowers and fruit. This severely affects the regeneration capacity of populations. The rare seedlings that emerge from this harsh system are subject to fire and indiscriminate grazing, which constitute challenging factors for survival. Debarking for medicinal purposes along with the uncontrolled and illegal logging of the best trees are serious additional threats for the long-term survival of Khaya populations. To test for NTFP harvesting impacts on pop- 
ulations, they should be classified not only on the basis of current harvesting intensity but also on harvesting histories and techniques. In this study, to assess the impact of bark and foliage harvest on $K$. senegalensis population dynamics, I compared the values of the stochastic growth rate, extinction probabilities, and vital rates among three groups of six populations with different harvest intensities and histories. I also compared the genetic heterozygosity and differentiation parameters among the same groups of populations to test the impact of harvest on the genetic diversity.

\section{Food Limitation in the Tropics: Starvation Events of Wedge-Tailed Shearwater Chicks Indicate Ability of Food to Regulate Reproductive Rates in Seabirds Aaron Hebshi ${ }^{13}$}

Previous studies have suggested that food availability, at least in non-El Niño years, does not regulate populations of open-ocean tropical seabirds. This supposition has been advanced by studies showing the wide variety of prey taken by topical seabirds and by studies showing that adults easily can increase food delivery when their brood numbers are manipulated. This study documents food shortage in Hawaiian Wedge-tailed Shearwaters (Puffinus pacificus) in two of the three breeding seasons studied. Chick growth rates showed significant negative anomalies during a 2- to 3-week period in August 2000 and a 2 -week period in September 2003. In addition, weekly mortality rates during those periods ranged up to $14 \%$ against a background mortality rate of $1-2 \%$. Wedge-tailed Shearwaters depend heavily upon skipjack tuna (Katsuwonus pelamis), which drive prey up to the ocean's surface. Food shortages likely correspond to temporary reductions of foraging skipjack tuna within the shearwaters' foraging range.

\section{Comparison of Two Metrosideros polymorpha (Gaud.) Varieties at a High-Altitude Site on Mauna Loa, Hawai'i \\ Fennifer Hoof ${ }^{14}$}

Metrosideros polymorpha (Gaud.) ('Ōhi'a lehua) is a major component of native Hawaiian forests. It can be found from sea level to the tree line, and it is capable of growing in extreme environments such as recent lava flows, mountain bogs, and high altitudes. It has a highly variable morphology in terms of leaf size, shape, coloration, and pubescence. Although pubescent- and glabrous-leaved varieties can be found sympatrically, pubescent leaves typify leaf morphology of high-

${ }^{13}$ Department of Zoology, University of Hawai'i at Mānoa, Honolulu, Hawai'i. Sponsor: David Duffy.

${ }^{14}$ Department of Botany, University of Hawai'i at Mānoa, Honolulu, Hawaíi. Sponsor: David Webb. altitude plants, and glabrous plants are characteristically found at middle altitudes and moderate climates. Glabrous plants are rare at the tree line on Hawai'i. At one site a population of approximately 11 glabrous $M$. polymorpha plants exists among numerous pubescent plants. In $M$. polymorpha, the presence of trichomes is hypothesized to have an adaptive significance. Anatomical and physiological research is under way to elucidate how glabrous $M$. polymoprba plants have adapted to exist in such an extreme environment. Anatomical measurements such as leaf and cuticle thickness, vessel diameter, and stomatal frequency are being considered. Physiological factors including stomatal conductance and transpiration rate are also being measured. 
Initial findings show that the glabrous variety of $M$. polymorpha being studied has a higher average stomatal conductance rate and more stomata per leaf area than the pubescent variety. Minimal differences have been recorded in internal leaf anatomy. Additional anatomical and physiological data are still being collected.

\section{Movements and Habitat Utilization of Octopus cyanea in Kāne'ohe Bay, Hawai'i Gayla Ivey ${ }^{15}$}

Octopus cyanea is the basis of an important artisinal fishery in Hawaiian waters and is by far the largest harvest component taken in Kāne'ohe Bay. However, very little basic behavioral and ecological data are available to assess the impact and sustainability of this fishery or to formulate appropriate management methods. For example, very little data exist on the home ranges, site fidelity, and habitat requirements of $O$. cyanea. This project aimed to address this lack of data by developing and employing ultrasonic telemetry techniques to describe the movement patterns of $O$. cyanea individuals in Kāne'ohe Bay. Laboratory investigations have led to a novel method of transmitter attachment for octopuses that provides reliable retention of the transmitter for between 6 and 14 days while having negligible effects on the animals' movements. Two preliminary trials have demonstrated the practicality of these methods in the field. Future field investigations will address the following questions: What are the daily movement patterns and home range sizes of Octopus cyanea in Kāne'ohe Bay? How are the observed movement patterns correlated with habitat or substrate type, and what benthic organisms are associated with those substrates? What are the den occupancy patterns of $O$. cyanea in Kāne'ohe Bay, and what degree of site fidelity is exhibited? The results of field investigations will be analyzed in the context of existing data on $O$. cyanea life history and bioenergetics and of the Kāne'ohe Bay fishery to form conclusions about the appropriateness and design of a marine reserve as a management tool for this fishery.

\section{Coral Larval Supply May Not Always Be Key to Recruitment Danielle Fayewardene ${ }^{16}$}

Newly settled coral spat of Pocillopora damicornis were set out experimentally using terra-cotta tiles on the subtidal reef at $\mathrm{Ha}-$ nauma Bay, a marine protected area. Although spat on vertically placed tiles survived better than those on horizontal tiles, overall survival of newly settled spat was low. This is because of the deposition of fine sand by turbulent waters smothering the juveniles on the tiles. This prevents successful larval recruit-

\footnotetext{
${ }^{15}$ Department of Zoology, and Hawaici Institute of Marine Biology, University of Hawai'i at Mānoa, Honolulu, Hawai'i. Sponsor: Kim Holland.

${ }^{16}$ Department of Zoology, University of Hawai'i at Mānoa, Honolulu, Hawai'i. Sponsor: Charles Birkeland.
}

ment from being prevalent at Hanauma Bay. Only $1.5 \%$ of the coral colonies have originated from sexual reproduction, and the great majority of small corals are asexual remnants of larger colonies. However, in terms of "genets" (genetic units), the sexually reproduced colonies outnumbered the clones. When sexual recruits were defined as colonies less than $5 \mathrm{~cm}$ in diameter, it matches the poor survival on tiles that only $0.1 \%$ of the total calculated colonies were recruits. Much of the research these days is focused on the connectivity of reefs by the dispersion of larvae, but it may be the case that larval recruitment is sometimes a small component of reproduction, even in some of the healthiest coral reefs. 


\section{Ecology and Impact of an Alien, Invasive Octocoral in Hawai'i Sam Kahng ${ }^{17}$}

In 2001, a deep-water survey of the Maui black coral beds discovered a large percentage of black coral colonies overgrown and smothered by an alien soft coral, Carijoa riisei. Until that time, $C$. riise $i$ was considered a relatively benign introduction colonizing underutilized habitat in shallow waters. In fact, very few introduced marine invertebrates are known to proliferate on coral reef communities, and the process of invasion on coral reef communities is poorly understood. A 2003 follow-up investigation confirmed that $C$. riisei was readily killing black corals (Antipathes dichotoma, A. grandis), proliferating at depth, and overgrowing large beds of plate corals (Leptoseris sp.). Relative abundance and distribution of $C$. riisei were compiled from submersible and remotely operated vehicle video data to quantify the ecological impact at depth. The data and observations suggest that the probability of $C$. riisei settlement and overgrowth on black corals increases with time and may be facilitated by other epifauna. The result is that the reproductively mature colonies are being killed differentially. Despite its emerging notoriety, little is known about the ecology $C$. riisei including its reproductive characteristics. Preliminary results from time-series analysis of gonad development of tagged colonies revealed that $C$. riisei is highly fecund and capable of continuously seeding the water column with larvae. Although $C$. riisei exhibits common soft coral reproductive characteristics, it also exhibits a regular incidence of simultaneous hermaphroditism-extremely rare in octocorals. Together with analysis of other life history traits and regional ecology of $C$. riisei, an integrated picture is emerging of a successful invader in a susceptible ecosystem.

\section{Temporal Changes in the Infaunal Community Surrounding a Hawaiian Mariculture Operation \\ Han Lee ${ }^{18}$}

Repeated benthic biomonitoring efforts in the vicinity of a Pacific Threadfin, Polydactylis sexfilis, mariculture venture has allowed us to examine eutrophic effects on the infaunal community. Polychaete infaunal communities from two sites near the point source were compared with those at reference stations beyond the range of fish feed and wastes.

\footnotetext{
${ }^{17}$ Department of Oceanography, University of Hawai'i at Mānoa, Honolulu, Hawai'i. Sponsor: Richard W.

${ }^{18}$ Department of Zoology, University of Hawaici at Mānoa, Honolulu, Hawai'i. Sponsor: Julie H. Bailey-
} Grigg. Brock.
Increasing abundances of two opportunistic polychaetes, Capitella capitata and Ophryotrocha adherens, resulted in decreasing ShannonWeiner diversity and Pielou's evenness values at impacted stations. Infaunal community changes are summarily illustrated by a nonmetric multidimensional scaling (MDS). High nematode abundances, low redox potentials, and low amphipod abundance correspond with the presence of polychaete indicators of organic pollution, changes in infaunal community structure, low species richness, and abundance in illustrating the mounting effects of fish mariculture on the south shore of O'ahu, Hawai'i. 


\section{Metazoan Hox Gene Evolution and Phylogenetic Position of the Chaetognaths David Q. Matus ${ }^{19}$}

We are interested in the evolution of anterior/posterior axial patterning and body plan formation throughout the Metazoa. Using a degenerate polymerase chain reaction approach, we have isolated developmental regulatory genes involved in axial patterning from the pelagic chaetognath Flaccisagitta enflata. These include 10 members of the Hox family and a ParaHox gene. Hox genes are developmental regulatory genes involved in body plan formation and are believed to have diversified before the last common bilaterian ancestor. Chaetognaths, or arrowworms, are marine animals that are ubiquitous and abundant members of oceanic zooplankton communities, yet their phylogenetic position within the Metazoa has remained enigmatic since Darwin's time. They possess a suite of morphological and devel- opmental characters that has made resolving their phylogenetic affinity within the Metazoa difficult utilizing traditional methodologies. However, recent molecular evidence that I have generated from structural and developmental regulatory genes suggests that they may occupy a basal position within the protostomes. Yet the presence of many deuterostome-like characteristics (holoblastic radial cleavage, enterocoely, a tripartite coelomic arrangement, a postanal tail, and a presumed posterior fate of the blastopore) suggests that their origins may lie even more basal to the protostome/deuterostome divergence. The study of developmental regulatory genes within this potential basal bilaterian will shed new light onto the evolution of animal body plans and axes formation at the base of the Bilateria.

\section{Algal Territories of Herbivorous Damselfish: Are They Detrimental to the Long-Term Persistence of a Coral Reef? \\ Sarah A. McTee 20}

Territorial damselfish of the genus Stegastes actively kill coral polyps to provide substrate for algal growth. These algal "gardens" act as both a shelter and the main food source for Stegastes. The number and extent of damselfish territories in the national park on Ofu, American Samoa, have generated concern that herbivorous damselfish may negatively affect the long-term persistence of coral reefs in that area. A number of studies elsewhere have shown that bioerosion of corals is greater inside damselfish territories than outside territories. It therefore seemed important to as-

${ }^{19}$ Department of Zoology, and Kewalo Marine Laboratory, University of Hawai'i at Mānoa, Honolulu, Hawai'i. Sponsor: Mark Q. Martindale.

${ }^{20}$ Hawai'i Cooperative Fishery Research Unit, University of Hawai'i at Mānoa, Honolulu, Hawai'i. Sponsors: James Parrish and Charles Birkeland. sess some aspects of the interactions among coral, damselfish, algae, and bioerosion at Ofu. The purpose of this research project was to examine closely some of the Stegastes territories found in a common coral, Acropora donei, and to assess the incidence of bioeroders inside and outside such territories. Major results of this study were as follows: (1) as the number of Stegastes in a territory increases, the volume of coral converted to algal garden increases; (2) the composition of invertebrate bioeroders is much the same inside and outside Stegastes territories; (3) there is a trend toward increased numbers of bioeroders at the center of territories; (4) corals in algal gardens harbor a significantly greater density of invertebrate bioeroders than corals outside territories; however, (5) corals inside and outside territories did not experience measurably different amounts of bioerosion. Although invertebrate bioeroders are more 
abundant in territories, results from this research do not clearly indicate that Stegastes are detrimental to the long-term persistence of Ofu's coral reef.

\section{Impacts of Invasive Ants on Wedge-Tailed Shearwater Chick Condition and Fledging Success \\ Sheldon Plentovich ${ }^{21}$}

An increasing geographical range, the ability to reach high densities, and the potential to disrupt ecosystems make invasive ants one of the most potentially harmful but unstudied threats to native ecosystems. Impacts of invasive ants may be especially noticeable on islands with no native social insects, such as the Hawaiian Islands. The big-headed ant, Pheidole megacephala, and the fire ant, Solenopsis geminate, are two of at least 44 species that have been introduced to Hawai' $i$ and are suspected of disrupting ecosystems. Neither is known to harm vertebrates in their native ranges; however, limited anecdotal observations from Hawai'i suggest that both species harm seabird chicks. We used the experimental control of ant numbers to investigate the influence of fire ants and big-headed ants on seabird condition, growth rates, and nesting success. Ants were controlled on one of two pairs of offshore islets using a proteinbased ant bait called AMDRO. Each pair of islets was dominated by a different ant species. Ant densities declined on treated islets while increasing or remaining relatively stable on the untreated islets. Injuries to seabird chicks were common on the islet pair dominated by fire ants, but no injuries were observed on islets dominated by big-headed ants. No difference in fledging success was detected on either islet pair. AMDRO may be used to control ant numbers and improve the condition and possibly the survival of seabird chicks in areas invaded by fire ants.

\section{Patterns of Water Uptake and Transpiration by Forest Plantations Teresa Restom ${ }^{22}$}

Alien tree plantations were introduced to Hawai' $i$ in the first half of the twentieth century to reduce the hydrological impacts that intensive sandalwood extraction and cattle ranching had caused on the watersheds in the 1800s. Since their introduction, the impact of tree plantations on the hydrological cycle of these ecosystems has not been evaluated. The overall goal of this project was to estimate the potential of these plantations to recharge groundwater in the mesic watershed of Honouliuli, O'ahu. This study focused on transpiration patterns and rates, depth of water uptake, and leaf area and soil mois-

\footnotetext{
${ }^{21}$ Department of Zoology, University of Hawai'i at Mānoa, Honolulu, Hawai'i. Sponsor: Sheila Conant.

${ }^{22}$ Department of Botany, University of Hawaili at Mānoa, Honolulu, Hawai'i. Sponsor: Guillermo Goldstein.
}

ture dynamics of forests dominated by three different alien species: Eucalyptus robusta, Fraxinus ubdei, and Casuarina glauca. The objectives were to assess differences in water uptake and transpiration of different species and their effect on whole-stand water use. Depth of water uptake, leaf area index (LAI), rainfall, soil moisture, and tree sap flow were measured in one stand dominated by each species between August 1998 and March 2002. A long period of drought was observed between January 2000 and October 2001. After rainfall levels increased, the $F$. ubdei stand exhibited higher soil moisture and faster recovery of LAI than the other two stands. The stand dominated by E. robusta had the slowest LAI recovery but the fastest recovery in sap flow. In the $C$. glauca stand, soil moisture and sap flow remained low 4 months after the end of the drought, indicating that 
C. glauca was less adapted to drought than the other species, probably due to its shallow water uptake and low soil infiltration rates. These characteristics resulted in highest transpiration rates in the stand dominated by
E. robusta and lowest in the stand dominated by C. glauca, supporting the hypothesis that forest hydrology is influenced by species composition.

\section{Movement Patterns of the Introduced Snapper Lutjanus kasmira and Native Goatfishes in Hawai'i Brett Schumacher ${ }^{23}$}

Anecdotal reports from commercial and recreational fishers in Hawai'i indicate that catches and population sizes of some native reef fish may have declined since the blue-line snapper, Lutjanus kasmira (family Lutjanidae), was introduced in the mid-1950s. This correlation led to the popular, though a priori, assertion that L. kasmira was responsible for these declines through competitive or predatory interactions with native fishes. This study focused on identifying evidence of potential competitive interactions functioning through spatial and temporal overlap between L. kasmira and three species of native goatfish (family Mullidae: Mulloidichtbys flavolineatus, M. vanicolensis, and Parupeneus multifasciatus) at well-established coral reef sites off the south shore of $\mathrm{O}^{\prime}$ ahu, Hawai'i. Acoustic transmitters were surgically implanted in specimens of each species, and their movements were monitored either from a surface vessel or by remote receivers placed in selected habitat areas. Results indicate that $L$. kasmira overlaps spatially with all of the species in this study to some degree. Data from remote monitors also suggest that site fidelity to resting areas may be greater than to feeding areas. Further investigations into spatiotemporal relationships and dietary interactions will continue to clarify these potential competitive and predator-prey relationships, and help to interpret their ecological importance.

\section{Identifying Determinants of Resistance to High Temperatures: Evidence from a Coral Transplant Experiment Lance Smith ${ }^{24}$}

Coral reef marine protected areas should include coral colonies and habitats that are resistant to high temperatures so that these areas can provide a basis for coral recovery from bleaching events. Identification of determinants of resistance is a critical step in establishing networks of marine protected areas that are likely to be most robust in the face of continuing climate change. We con-

${ }^{23}$ Hawai'i Cooperative Fishery Research Unit, University of Hawai'i at Mānoa, Honolulu, Hawai'i. Sponsor: James Parrish.

${ }^{24}$ Hawai'i Cooperative Fishery Research Unit, University of Hawai'i at Mānoa, Honolulu, Hawai'i. Sponsor: Charles Birkeland. ducted a coral transplant experiment in Ofu Lagoon, American Samoa, to test for resistance to high temperatures. The lagoon consists of a series of pools that vary in thermal conditions, with temperatures in some pools reaching $35^{\circ} \mathrm{C}$ and fluctuating daily by $>6^{\circ} \mathrm{C}$. Yet the pools support diverse coral communities, including many species thought to be sensitive to high temperatures, such as Acropora, Pocillopora, and Millepora spp. Nubbins of Pocillopora damicornis and Porites cylindrica were obtained from the deepest pool, dyed with Alizarin red S for measuring growth, and transplanted to the shallowest pool and a pool intermediate in depth, as well as back into the pool of origin. Water temperatures were 
recorded hourly at the three sites during the 1 -yr period, and other water quality and physical characteristics were studied at the three sites. The shallowest site had the highest daily maximum temperatures, the greatest duration of high temperatures, and the greatest daily fluctuations of temperatures of the three study sites. However, transplants of both species had the highest growth rates at the shallowest site, and $P$. damicornis had the highest survival rate at that site. Water motion and dissolved oxygen levels were higher at the shallowest site than at the other two transplant sites, suggesting that one or both of these extrinsic factors enhance the resistance of corals to high temperatures.

\section{Deep Thoughts in Muddy Waters: Deep-Water Macroalgae as Water Clarity Bio-Indicators? ${ }^{25}$ \\ Heather Spalding ${ }^{26}$}

Given suitable substrate, light is generally considered the controlling factor limiting macroalgal growth with increasing depth in temperate waters. Any long-term changes in light availability at the lower depth limits of deep-water (30-80 m) macroalgal assemblages could affect their depth distribution, species composition, and/or abundance. Thus, it has been suggested that a temporal comparison of deep-water macroalgal assemblages could be used to monitor the biological impacts of long-term coastal marine perturbations causing decreased water clarity. To test this hypothesis, the Carmel River in central California was used as a natural turbidity gradient. The lower depth limits and abundance of deep-water macroalgae were surveyed with the ROV Ventana at various distances from the river and compared with data from 14 other sites unaffected by river output. Diffuse attenuation coefficients were calculated from irradiance profiles at each site. It was hypothesized that sites close to the river mouth would have increased light attenuation and therefore shallower depth limits, compared with sites farther away with decreased light attenuation and lower depth limits. Deep-water macroalgae were less abundant and had shallower depth limits near the river mouth, but surprisingly there were no significant differences in light attenuation between sites. Decreased macroalgal abundance appeared to be the result of burial from sedimentation, thus masking any possible effects from increased light attenuation. Similar changes were not apparent at $\leq 30-\mathrm{m}$ depths, suggesting that deep-water macroalgae may be affected by processes, such as sedimentation, not evident in shallower water.

\section{Mapping of a Novel Gene Mutation in $r c$ Mice That Results in Cyclic Hair Loss and a Possible Keratinocyte Stem Cell Fate Switch ${ }^{27}$ Kornelia M. Szauter ${ }^{28}$}

\footnotetext{
${ }^{25}$ Work done at Moss Landing Marine Laboratories. ${ }^{26}$ Department of Botany, University of Hawai'i at Mānoa, Honolulu, Hawai'i. Sponsor: Celia Smith.

${ }_{27}$ Coauthors: Peter Racz, Qing-Ping He, Eszter Pankotai, Ben Fogelgren, Darlene Ramones, and Gregory Young.

${ }^{28}$ Cardiovascular Research Center, John A. Burns School of Medicine, University of Hawai'i at Mānoa, Honolulu, Hawai'i. Sponsors: Tongyu Cao, Katalin Csiszar.
}

The hair follicles are an ideal model system for studying stem cell fate determination and differentiation. The multipotent keratinocyte stem cells (KSCs) residing in the hair follicles give rise to the sebaceous glands, are responsible for the cyclic growth of the hair follicles, and play a role in epidermal wound healing. KSC fate is determined by the coordinated functioning of several signaling pathways, and 
alterations in these pathways may result in defects in KSC differentiation. Rough coat mutant mice display phenotypes that suggest a switch in KSC fate. Rough coat $(r c)$ is a recessive mutation that arose spontaneously in the C57BL/6 strain at the Jackson Laboratory. The $r c$ mice have unkempt hair at weaning age and develop cyclic and progressive hair loss. Histologically, the $r c$ phenotype is characterized by follicular atrophy and hypertrophic sebaceous glands. At later stages the mice develop defects in epidermal wound healing. The $r c$ was previously mapped on chromosome 9; however, the mutation has not been identified. In this study, we aimed to identify the mutation causing the $r c$ phenotype. We carried out high-resolution linkage analysis using backcross mice and defined and reduced the $r c$ interval to 1.1 megabases. We are currently constructing a physical map of the $r c$ interval and analyzing candidate genes for mutations. We expect to discover either a novel gene or a novel function of a known gene involved in KSC fate determination.

\section{Between Hawaiian Tides: A Surprising Diversity in O'ahu's Intertidal ${ }^{29}$ Chela 7. Zabin ${ }^{30}$}

Hawai'i's tidal range is about one-third that of California's, and in many places wave splash is higher than the highest tide. Perhaps because of this, the prevailing view among scientists seems to be that the intertidal in Hawai' $i$ is a species-poor, marginal habitat. As a result, the Hawaiian intertidal has received little scientific study compared with coral reef areas and even less conservation attention. With no published field guides or species lists to guide us, we surveyed five intertidal sites around the island of O'ahu with 54 ninth-grade students from a public school in Honolulu. Students collected and, with the assistance of graduate students and volunteers from the Bishop Museum, identified over 340 species of macroalgae, fish, and invertebrates.
Six additional sites were surveyed by one of the authors, bringing the total list of invertebrate species alone to 312 . For invertebrates, this level of diversity parallels that from several mainland West Coast sites and is undoubtedly an underestimate of the actual diversity. Endemism was in line with or higher than levels reported for subtidal species, and numbers of invasive species were also high compared with those from rocky intertidal systems elsewhere. Juveniles of several reef-fish species were found in tide pools, illustrating a link between the intertidal zone and the reef. Student projects this year will include quantitative counts, surveys of new sites, and an attempt to quantify human impacts in the intertidal zone.

\footnotetext{
${ }^{29}$ Coathors: Erin P. Baumgartner, Curriculum Research and Development Group, University of Hawai'i, and Dawn N. Adams, Department of Botany, University of Hawai'i.

${ }^{30}$ Department of Zoology, University of Hawai'i at Mānoa, Honolulu, Hawai'i. Sponsor: Andrew Taylor.
} 
